\title{
O Curso de Pedagogia nas universidades federais do Estado de Minas GERAIS: REFLEXÕES ACERCA DO ESPAÇO DA EDUCAÇÃO INFANTIL NOS CURRÍCULOS DE FORMAÇÃO INICIAL
}

\author{
EL CURSO dE PEDAGogía de LAS UNIVERSIDADES FEDERALES DE MiNAS GERAIS: \\ REFLEXIONES SOBRE EL ESPACIO DE LA EDUCACIÓN INFANTIL EN LOS PROGRAMAS DE \\ FORMACIÓN INICIAL
}

THE COURSE OF PEDAGOGY IN THE FEDERAL UNIVERSITIES OF THE STATE OF MINAS GERAIS: REFLECTIONS ON THE SPACE OF EARLY CHILDHOOD EDUCATION IN INITIAL FORMATION

RESUMO: Este artigo propõe analisar o espaço curricular conferido à educação infantil nos cursos de formação inicial das universidades federais do Estado de Minas Gerais. A metodologia utilizada caracterizou-se como uma pesquisa qualitativa de cunho documental por meio da análise dos currículos dos cursos. A reflexão está pautada nos aportes teóricos da Sociologia da Infância que traz contribuições para a proposição de uma pedagogia que considere as especificidades da criança. A análise dos dados encontrados nos aponta que há uma diversidade de composições acerca das disciplinas voltadas às questões da educação infantil. Essa diversidade se caracteriza pela variação na carga horária, nas nomenclaturas e na quantidade de disciplinas que são ofertadas. Isso não contribui para a constituição de um corpus teórico específico voltado para o campo da educação infantil e a formação de professores para essa faixa etária no Brasil. Nesse sentido, encontramos ainda lacunas no que se refere à organização das universidades quanto à área da educação infantil a ser contemplada na formação inicial em pedagogia e que reclama por políticas governamentais que possam contribuir para a constituição de um campo de formação específico.

PALAVRAS-CHAVE: Educação infantil. Organização curricular. Curso de pedagogia.

RESUMEN: Este artículo tiene como objetivo analizar el espacio curricular de la educación infantil en los cursos de formación inicial de las universidades federales de Minas Gerais. La metodología utilizada se caracteriza por ser una investigación cualitativa en pruebas documentales mediante el análisis de los planes de estudio de los cursos. La reflexión es guiado en aportaciones teóricas de la sociología de la infancia que trae contribuciones a la proposición de una pedagogía que tenga en cuenta las circunstancias particulares del niño. El análisis de los datos encontrados nos muestra que hay una diversidad de composiciones sobre los temas orientados a los temas de la educación infantil. Esta diversidad se caracteriza por la variación de la carga de

\footnotetext{
1 Docente Programa de Pós-Graduação em Educação da Universidade Federal de Alfenas (UNIFAL-MG). Email: fabiana.oliveiraunifal@gmail.com

${ }^{2}$ Mestranda pela Universidade Federal de Alfenas (UNIFAL-MG) no Programa de Pós-Graduação em Educação. Email: giandrade21@hotmail.com
} 
trabajo, las nomenclaturas y la cantidad de cursos que se ofrecen. Esto no contribuye a la creación de un cuerpo teórico específico frente al campo de la educación infantil y la formación de profesores para este grupo de edad en Brasil. En este sentido, todavía encontramos lagunas en cuanto a la organización de las universidades y el área de la educación infantil a considerar en la formación inicial en la pedagogía y pide que las políticas del gobierno que pueden contribuir a la creación de un curso de formación específico.

PALABRAS CLAVE: La educación de la primera infancia. La organización curricular. Curso de Pedagogía.

ABSTRACT: This article proposes to analyze the curricular space given to early childhood education in the initial formation of the federal universities of the State of Minas Gerais. The methodology used was characterized as a qualitative documentary research through the analysis of the curriculum of the courses. The reflection is based on the theoretical contributions of the Sociology of Childhood that brings contributions for the proposition of a pedagogy that considers the specificities of the child. The analysis of the data found in us points out that there is a diversity of compositions about the disciplines focused on the issues of early childhood education. This diversity is characterized by the variation in the workload, in the nomenclatures and in the quantity of subjects that are offered. This does not contribute to the constitution of a specific theoretical corpus focused on the field of early childhood education and teacher training for this age group in Brazil. In this sense, we still find gaps regarding the organization of universities in the area of early childhood education to be contemplated in the initial formation in pedagogy and that calls for governmental policies that can contribute to the constitution of a specific field of formation.

KEYWORDS: Child education. Curricular organization. Pedagogy course.

\section{Introdução}

A presente reflexão tem como objetivo analisar o espaço curricular conferido à educação infantil nos cursos de formação inicial das universidades federais mineiras. Apresentamos a presente pesquisa para conhecermos como os currículos dos cursos de Pedagogia nessas universidades têm sido organizados em relação à formação das professoras da educação infantil. No decorrer do texto utilizamos a expressão "professoras" por se tratar de um público majoritariamente feminino.

O currículo é parte central na formação dos indivíduos, pois ordena de forma normativa e regulatória aquilo que deve fazer parte da formação dos indivíduos, seja nas escolas ou nas instituições de ensino superior, e se constitui uma fonte de poder no 
estabelecimento do que é considerado "essencial" para a aprendizagem e constituição dos saberes instituídos culturalmente, ou seja, um "currículo prescritivo" segundo Goodson (1997).

Assim, de acordo com Macedo (2012, p.15), a forma como o currículo ainda é configurado e concebido "se constitui num dos artefatos educacionais dos mais iluministas, autoritários e excludentes". Neste sentido, é preciso estabelecer um questionamento acerca destas verdades instituídas sobre as representações do currículo que levam a determinadas práticas já cristalizadas e que produzem determinadas subjetividades assujeitadas, e que se distanciam do processo reflexivo e crítico necessário à atual conjuntura do mundo contemporâneo para a formação de sujeitos atuantes, competentes e situados historicamente para uma sociedade que se pretenda mais democrática.

Desta forma, estamos nos pautando em uma concepção de currículo que se distancia da ideia de neutralidade que pode carregar e das ideologias constituintes. Uma concepção de currículo que esteja assentada em uma proposta de conhecimento como algo mutável e que é construído, assim, o currículo não é entendido como uma sequência rígida e hierárquica de conteúdos, mas sim, um currículo que organiza globalmente as temáticas trabalhadas de forma não fragmentada, ou seja, para além de uma lista de conteúdos.

Da mesma forma, questiona-se a organização curricular pautada na "lógica do descarte e da substituição", que torna a tradição algo distante e desimportante, mas ao mesmo tempo temos que tomar cuidado com "o novo pronto ou epistemologicamente delirante" que se caracteriza por uma exacerbação pela novidade, mas sem criticidade (MACEDO, 2012).

Assim, nos perguntamos: o que tem sido oferecido em um currículo para a formação de professoras das crianças de 0 a 5 anos? O que é considerado relevante e quais seriam as "ausências presentes" nesses currículos?

A discussão sobre a formação profissional das professoras da educação infantil ganhou força no nosso país após as diversas conquistas ocorridas pelo menos no nível da legislação, que reconheceu o direito da educação infantil à criança, ou seja, deixou de ser um direito da mãe trabalhadora, passando agora a considerar a criança como sujeito de direitos, apesar de não ser obrigatório, mas é dever do Estado.

Em seguida tivemos o Estatuto da Criança e do Adolescente que reforçou esse direito da criança e, por último, tivemos a Lei de Diretrizes e Bases da Educação 
Nacional (LDB 9394/96) que tornou a educação infantil a primeira etapa da educação básica, marcando para a creche e a pré-escola as funções de cuidado e educação, visando desfazer a ideia cristalizada de que tínhamos na creche apenas cuidado e na préescola somente educação. Dentro de todo este novo contexto, a formação dos profissionais que atuam na educação infantil passou a ser considerada um aspecto fundamental para a oferta de uma educação infantil de qualidade.

Para essa qualificação das profissionais que atuam na educação infantil não podemos deixar de refletir sobre o ensino ofertado nos cursos de formação inicial. O curso normal desde os anos 30 visava a formação do professor para atuar nas escolas primárias e na pré-escola; segundo Kishimoto (1999), desde essa época, a Universidade Federal do Rio de Janeiro e a Universidade Federal do Paraná já possuíam cursos em nível superior para profissionais da educação infantil, com a licenciatura em educação pré-escolar; no entanto, os pesquisadores da área apontam vários dilemas que esta formação atualmente ainda carrega e que precisam ser discutidos. Isso acaba sendo o reflexo da ausência de uma política nacional para a educação infantil no Brasil, apesar dos avanços da legislação atual.

A partir da Lei de Diretrizes e Bases da Educação Nacional (LDB 9394/96) passamos a ter duas instituições responsáveis pela formação de professores no nosso país: os Institutos Superiores de Educação, com a oferta do curso normal superior, juntamente com as Instituições de Ensino Superiores, com o curso de Pedagogia. Esta mesma legislação exige como formação o curso de licenciatura em Pedagogia, mas também admite-se como formação mínima a oferecida na modalidade normal para atuação na educação infantil e nas séries iniciais do ensino fundamental.

Ainda é uma realidade em nosso país encontrarmos um número elevado de profissionais leigas que atuam na educação infantil sem a formação mínima exigida ou mesmo sem ter concluído o ensino fundamental. Neste sentido, se faz urgente pensar na formação destas profissionais que irão atuar na educação infantil e daquelas que já estão atuando e precisam de formação em serviço, para que realmente tenhamos uma educação infantil de qualidade, que é um direito de todas as crianças.

Kishimoto (2005) foi uma das primeiras pesquisadoras que refletiram acerca da formação das professoras da educação infantil, nos apresenta que os cursos de formação possuem pouca clareza do perfil profissional desejado, gerando inclusive, uma formação que não respeita as especificidades da educação infantil, pois as práticas adotadas nos cursos não possuem diferenciação para formar profissionais para atuarem na educação 
infantil e no ensino fundamental. Prática esta encontrada desde as escolas normais e que necessita ser revista.

Ainda segundo Kishimoto (2008), uma das críticas mais contundentes contra a formação profissional nas universidades tem a ver com a sua natureza disciplinar. E essa organização disciplinar conduz os futuros professores a organizarem o ensino desta forma, o que acarreta efeitos muitos negativos para a organização do currículo na educação infantil, pois a criança pequena aprende de forma contextualizada, observando, quando brinca, interagindo com o ambiente que a cerca, e não de forma fragmentada.

Nesse sentido, de acordo com Formosinho (2008), o processo de universitarização de formação de professores se caracterizou como um processo de academicização, transformando a formação dessas professoras numa formação teórica e afastada das preocupações pragmáticas, isto é, aos componentes profissionalizantes. A docência, segundo o autor, implica ao mesmo tempo um desempenho intelectual e técnico. Formosinho (2005, p.174) conceitua 'academicização' como "o processo de construção de uma lógica predominantemente acadêmica numa instituição que também deve se preocupar com a formação profissional”.

Outro problema está relacionado ao distanciamento com as práticas pedagógicas decorrente de uma tradição disciplinar-verbalista, não considerando a prática enquanto eixo articulador da formação, enquanto momento articulador da teoria e da prática na formação de um profissional crítico-reflexivo e pesquisador da sua prática e da realidade que irá atuar (KISHIMOTO, 2005; FORMOSINHO, 2005).

A partir desses questionamentos apresentados à formação inicial especificamente por meio desses estudos de pesquisadores renomados que apresentamos a presente pesquisa, para conhecermos como os currículos dos cursos de Pedagogia das Universidades Federais do Estado de Minas Gerais têm sido organizados em relação à formação das professoras da educação infantil.

Para além das críticas já apresentadas em pesquisas anteriores, buscamos avançar no sentido de responder algumas questões: o que efetivamente tem sido tratado em matéria de educação infantil nos currículos dos cursos de formação inicial? Quais são as disciplinas presentes nos currículos dos cursos de formação inicial? Qual é carga horária dessas disciplinas? Quando os estágios são ofertados e quais são as suas cargas horárias? 
A reflexão está organizada em três partes que se complementam: na primeira parte é apresentada uma discussão a partir da qual se ancora o nosso referencial teórico para se pensar a organização curricular das disciplinas voltadas à docência na educação infantil; em seguida, apresentamos os aspectos metodológicos da pesquisa e, por último, a análise dos currículos visando responder as questões em pauta colocadas pelo presente estudo.

\section{Quais as contribuições que a Sociologia da Infância pode trazer para se pensar o currículo nos cursos de pedagogia para as disciplinas de educação infantil?}

Inicialmente, é importante pontuar que esse campo de estudos denominado de Sociologia da Infância vem ganhando cada vez mais espaço nas pesquisas com crianças e na área da educação infantil; consequentemente, também pode nos apontar algumas reflexões acerca da criança e da infância que nos indiquem perspectivas a serem revistas e até mesmo incorporadas no modo como até então as disciplinas presentes nos currículos de pedagogia têm considerado o grupo geracional das crianças, o seu processo de socialização, o brincar e a sua participação nas questões associadas às práticas na educação infantil.

Quando refletimos acerca do surgimento da Sociologia da Infância precisamos considerar que isso só foi possível graças a uma abertura no campo das ideias sociológicas que, até então, não tinham reservado às crianças uma atenção específica, pois sempre eram estudadas como um fenômeno interligado à escola e à família e atrelada à discussão sobre a socialização da criança como uma forma de inculcação dos valores da sociedade adulta.

Os sociólogos se voltavam para o estudo das influências desta socialização na vida das crianças a partir de uma perspectiva estrutural-funcional. Especialmente a sociologia da educação, permaneceu durante um longo período presa à definição durkheimiana de imposição dos valores adultos sobre a criança, levando estas a permanecerem no silêncio, 'mudas', ou seja, em uma posição marginalizada e passiva diante do mundo adulto.

Os sociólogos da infância de um modo geral concebem o conceito de socialização a partir de um entendimento diferente do conceito utilizado por Durkheim, 
pois esta socialização estaria atrelada a uma visão vertical a partir da qual a criança absorve o mundo adulto com suas regras e valores por meio da ação de uma geração sobre a outra (PLAISANCE, 2005; JAMES e JAMES, 2004; PROUT, 2005).

Neste sentido, de acordo com Plaisance (2005), as concepções atuais sobre a socialização das crianças concordam que essa se dá por meio de múltiplas negociações com seus pares (crianças-crianças) e também com os adultos, contribuindo para a construção da identidade do sujeito.

Segundo Sirota (2001), a redescoberta da sociologia interacionista e as abordagens construcionistas forneceram os paradigmas teóricos para essa nova perspectiva de compreensão da criança e da infância, assim "essa releitura crítica do conceito de socialização e de suas definições funcionalistas leva a considerar a criança como ator" (p. 4). Desta forma, propõe-se um outro modelo baseado numa concepção interacionista que implica considerar a criança "como sujeito social, que participa de sua própria socialização, assim como da reprodução e da transformação da sociedade" (MOLLO-BOUVIER, 2005, p. 393).

A partir desta vertente, passamos a compreender a infância como uma categoria social de tipo geracional, e a criança, como os atores sociais que integram essa categoria. Recusando uma concepção uniforme da infância, pois mesmo considerando os fatores de homogeneidade entre as crianças como uma categoria do tipo geracional própria, os fatores de heterogeneidade também devem ser considerados (classe social, gênero, etnia, religião, etc), pois os diferentes espaços estruturais diferenciam sobremaneira as crianças, por isso podemos falar em infâncias no plural (SARMENTO, 2005 e JAMES e JAMES, 2004).

Considerando essa criança enquanto um ator social que vive suas várias infâncias, um fator essencial a ser destacado são as culturas infantis, para compreendermos o campo de ação das crianças dentro da categoria geracional. Por culturas infantis Sarmento entende que são "um conjunto estável de atividades ou rotinas, artefatos, valores e ideias que as crianças produzem e partilham em interação com os seus pare" (CORSARO e ELDER, 1990 citado por SARMENTO, 2005, p. 373).

Estas culturas infantis não são o produto exclusivo do mundo simbólico da infância, pois não é, de acordo com Sarmento, um universo fechado e autônomo, sendo permeável por toda a influência dos modos de vida dos adultos, dos processos de institucionalização, da influência da mídia, do consumo e da indústria cultural para as 
crianças, com seus brinquedos eletrônicos, como vídeo games, e também a utilização de computadores e da internet (SARMENTO, 2007).

A partir disto podemos compreender por meio desta perspectiva que a criança inflete o mundo social que ela vive de maneira singular, pois elas produzem culturas infantis que são constituídas a partir de um movimento de produção e reprodução da cultura que Corsaro (2011) denomina "reprodução interpretativa", pois as crianças fazem uma interpretação singular do mundo adulto (social), sendo um elemento distintivo da categoria geracional (Sarmento, 2007).

Nesse sentido, as discussões apresentadas anteriormente fornecem subsídios para se repensar os currículos dos cursos de pedagogia, pois a formação específica do profissional da educação infantil deve dar abertura à pluralidade de saberes que envolve a docência na educação infantil, considerando as questões de subjetividade, a construção da autonomia, a diversidade cultural, de gênero, classe social e raça/etnia, pois estas são constituidoras do ambiente da educação infantil e devem ser consideradas no entendimento de uma criança concreta/real e não universal/abstrata.

O necessário conhecimento das culturas infantis que os momentos de observação e participação nas práticas cotidianas da educação infantil poderão possibilitar à futura profissional um maior conhecimento acerca das crianças, do seu modo de brincar, das suas teorias, dos seus desenhos. Esses dados são relevantes, pois a partir disso, a criança está nos apresentando uma gama variada de elementos para buscarmos entender o que estão compreendendo sobre o mundo adulto.

\section{A pesquisa}

A metodologia adotada para a execução desta pesquisa fundamenta-se na pesquisa qualitativa de cunho bibliográfica/documental, pois trata-se da análise de currículos e de programas de cursos de Pedagogia de universidades do Estado de Minas Gerais.

O Estado de Minas Gerais possui onze instituições federais de ensino superior, sendo que dessas, nove possuem o curso de Pedagogia e que, portanto, compuseram o estudo das dinâmicas curriculares. A análise se deu especificamente a partir dessas dinâmicas curriculares, visando analisar o espaço conferido à educação infantil nesses cursos. As nove instituições serão denominadas nesta pesquisa a partir de uma numeração 
específica que poderá ajudar a organizar os dados, assim, utilizaremos o seguinte tratamento: IES 1, IES 2, até a última, IES 9.

Os dados relacionados aos documentos foram divididos em três categorias de análise. De acordo com Gomes (1994, p.70) “as categorias são empregadas para se estabelecer classificações [...] trabalhar com elas significa agrupar ideias, elementos ou expressões em torno de um conceito capaz de abranger tudo isso".

As três categorias de análise foram as seguintes: componentes curriculares de conteúdos específicos e metodologias; componentes curriculares associados ao estágio e temáticas presentes nas ementas e nos programas.

As categorias estabelecidas foram criadas a partir de um princípio único de classificação por meio dos assuntos recorrentes nos documentos, sendo que no conjunto todos os princípios e artigos foram incluídos, mas considerando que nenhum artigo ou princípio fosse colocado em mais de uma categoria.

\section{Os currículos dos cursos de Pedagogia nas Universidades Federais Mineiras}

Nos currículos analisados das nove instituições federais de ensino superior do Estado de Minas Gerais podemos considerar que há uma diversidade de composições acerca das disciplinas voltadas às questões da educação infantil. Essa diversidade se caracteriza pela variação na carga horária, nas nomenclaturas e na quantidade de disciplinas que são ofertadas. Vejamos o quadro a seguir:

Quadro 1 - componentes curriculares de conteúdos específicos e metodologias

\begin{tabular}{|c|c|c|c|}
\hline INSTITUIÇÃO & DISCIPLINAS & CARGA HORÁRIA & PERÍODO \\
\hline \multirow[t]{3}{*}{ IES 1} & $\begin{array}{l}\text { Fundamentos históricos e políticos da } \\
\text { educação infantil }\end{array}$ & 60 horas & $3^{\circ}$ período \\
\hline & $\begin{array}{l}\text { Conhecimento e currículo na educação } \\
\text { infantil }\end{array}$ & 75 horas & $4^{\circ}$ período \\
\hline & $\begin{array}{llll}\text { Organização didática } & \text { da } & \text { educação } \\
\text { infantil }\end{array}$ & 75 horas & $6^{\circ}$ período \\
\hline \multirow[t]{3}{*}{ IES 2} & Políticas de educação para a infância & ${ }^{3}$ & $2^{\circ}$ período \\
\hline & $\begin{array}{l}\text { Fundamentos teórico-metodológicos em } \\
\text { educação infantil I }\end{array}$ & - & $2^{\circ}$ período \\
\hline & $\begin{array}{l}\text { Fundamentos teórico-metodológicos em } \\
\text { educação infantil II }\end{array}$ & - & $3^{\circ}$ período \\
\hline \multirow[t]{3}{*}{ IES 3} & História da educação II & 45 horas & $2^{\circ}$ período \\
\hline & Políticas públicas em educação & 60 horas & $3^{\circ}$ período \\
\hline & $\begin{array}{l}\text { Crescimento e desenvolvimento da } \\
\text { criança I }\end{array}$ & 60 horas & $3^{\circ}$ período \\
\hline
\end{tabular}

${ }^{3}$ Não foi encontrado no Projeto Pedagógico dessa instituição a carga horária das disciplinas. 


\begin{tabular}{|c|c|c|c|}
\hline & $\begin{array}{l}\text { Crescimento e desenvolvimento da } \\
\text { criança II }\end{array}$ & 60 horas & $3^{\circ}$ período \\
\hline & $\begin{array}{l}\text { Crescimento e desenvolvimento da } \\
\text { criança III }\end{array}$ & 60 horas & $3^{\circ}$ período \\
\hline & Saúde, alimentação e nutrição II & 60 horas & $3^{\circ}$ período \\
\hline & $\begin{array}{l}\text { Jogos, brinquedos, brincadeiras: o } \\
\text { lúdico e o processo de desenvolvimento } \\
\text { infantil I }\end{array}$ & 45 horas & $4^{\circ}$ período \\
\hline & $\begin{array}{l}\text { Jogos, brinquedos, brincadeiras: o } \\
\text { lúdico e o processo de desenvolvimento } \\
\text { infantil II }\end{array}$ & 45 horas & $4^{\circ}$ período \\
\hline & A criança, a família e a escola & 60 horas & $4^{\circ}$ período \\
\hline & Currículo e escola & 60 horas & $5^{\circ}$ período \\
\hline & Linguagem e pensamento I & 60 horas & $6^{\circ}$ período \\
\hline & Linguagem e pensamento II & 60 horas & $6^{\circ}$ período \\
\hline \multirow[t]{5}{*}{ IES 4} & Estudo sobre a infância & 60 horas & $4^{\circ}$ período \\
\hline & Organização da educação infantil & 30 horas & $5^{\circ}$ período \\
\hline & Arte na educação infantil & 60horas & $7^{\circ}$ período \\
\hline & Didática na educação infantil & 60 horas & $7^{\circ}$ período \\
\hline & $\begin{array}{l}\text { Observatório de currículo: educação } \\
\text { infantil }\end{array}$ & 30 horas & $8^{\circ}$ período \\
\hline IES 5 & Educação e saúde & 45 horas & $8^{\circ}$ período \\
\hline \multirow[t]{6}{*}{ IES 6} & $\begin{array}{l}\text { Organização e política da educação } \\
\text { brasileira }\end{array}$ & 72 horas & $3^{\circ}$ período \\
\hline & $\begin{array}{l}\text { Fundamentos e didática da educação } \\
\text { infantil I }\end{array}$ & 72 horas & $4^{\circ}$ período \\
\hline & $\begin{array}{l}\text { Currículo e planejamento na educação } \\
\text { infantil }\end{array}$ & 36 horas & $4^{\circ}$ período \\
\hline & $\begin{array}{l}\text { Práticas de avaliação na educação } \\
\text { infantil }\end{array}$ & 36 horas & $5^{\circ}$ período \\
\hline & $\begin{array}{l}\text { Fundamentos e didática da educação } \\
\text { infantil II }\end{array}$ & 72 horas & $5^{\circ}$ período \\
\hline & Ludicidade e desenvolvimento infantil & 72 horas & $6^{\circ}$ período \\
\hline \multirow[t]{2}{*}{ IES 7} & Fundamentos da educação infantil I & 60 horas & $3^{\circ}$ período \\
\hline & Fundamentos da educação infantil II & 60 horas & $4^{\circ}$ período \\
\hline \multirow[t]{2}{*}{ IES 8} & $\begin{array}{l}\text { Princípios e métodos da educação } \\
\text { infantil }\end{array}$ & 75 horas & $1^{\circ}$ período \\
\hline & Sociedade, cultura e infância & 75 horas & $5^{\circ}$ período \\
\hline \multirow[t]{4}{*}{ IES 9} & Fundamentos da educação infantil & 60 horas & $2^{\circ}$ período \\
\hline & Jogos, brinquedos e brincadeiras & 30 horas & $8^{\circ}$ período \\
\hline & Currículo e educação infantil & 30 horas & $9^{\circ}$ período \\
\hline & Direito à infância e educação & 30 horas & $9^{\circ}$ período \\
\hline
\end{tabular}

Fonte: Elaboração própria a partir dos Projetos Pedagógicos dos cursos analisados.

Em relação aos períodos em que as disciplinas são ofertadas, percebe-se que nas IES 1, 3, 6 e 7, as disciplinas aparecem a partir do segundo semestre do curso de Pedagogia, ou seja, do $2^{\circ}$ período em diante até o $6^{\circ}$ período do curso. Já na IES 2 as 
disciplinas estão concentradas somente no $2^{\circ}$ e $3^{\circ}$ períodos. Enquanto que, na IES 4 , as disciplinas estão organizadas no $4^{\circ}, 5^{\circ}, 7^{\circ}$ e $8^{\circ}$ períodos.

Em contrapartida, nas IES 8 e 9 as disciplinas demonstraram um distanciamento umas das outras, pois na IES 8 há uma disciplina no $1^{\circ}$ período e outra no $5^{\circ}$ período, e na IES 9 há uma disciplina no $2^{\circ}$ período e as demais no $8^{\circ}$ e $9^{\circ}$ período, pois o projeto pedagógico analisado está dividido em dez períodos. A IES 5 apresenta somente uma disciplina referente à educação infantil no $8^{\circ}$ período do curso de Pedagogia. Foi a menor carga horária encontrada dentre as universidades analisadas.

Em relação aos dados encontrados, pudemos observar que a IES 3 possui uma maior quantidade de disciplinas com o tema da educação infantil, totalizando doze disciplinas, sendo que na IES 5, identificamos somente uma disciplina sobre esta questão, como já foi apontado anteriormente. Nas demais universidades, encontramos uma variância de duas até seis disciplinas envolvendo a educação infantil. Este fato corrobora para uma ideia de que cada universidade segue um entendimento diferenciado quando se trata de disciplinas sobre a educação infantil. Também há uma variância da carga horária destas disciplinas, dado que a mínima quantidade de horas é de trinta, e a máxima é de setenta e cinco horas.

Consideramos importante fazer um cálculo sobre a porcentagem das disciplinas em relação à carga horária total do curso de pedagogia de cada universidade, mas sem contabilizar a disciplina de estágio específica, para conhecer qual é a porcentagem, do total de horas do curso de pedagogia, destinados à formação da professora da educação infantil.

Constata-se que, apesar de cada universidade apresentar uma variância da carga horária total do curso, entre 3.819h (máxima) e 3.200h (mínima), a IES 3 apresenta a maior porcentagem, com $17,67 \%$ de disciplinas voltadas para a educação infantil.

Em contrapartida, a IES 5 exibe a menor porcentagem, com 1,38\% do curso que oferece disciplina na área. A IES 6 mostra a segunda maior porcentagem, de 9,95\% de disciplinas, em seguida encontramos a IES 4 e a IES 1 com respectivamente 7,34\% e 6,37\%. Já a IES 8 mostra uma porcentagem de 3,93\% de disciplinas com o assunto da educação infantil, sendo que a IES 7 e a IES 9 apontam a mesma porcentagem, de $3,75 \%$ de disciplinas.

No entanto, é preciso considerar separadamente o número de disciplinas ofertadas e sua carga horária total: As IES 1 e 3 possuem três disciplinas, especificamente quanto à primeira IES, a mesma contabiliza 210 horas. As IES 4, 6 e 9 
possuem respectivamente cinco, seis e quatro disciplinas que totalizam cada uma 240; 360; e 150 horas. As IES 5, 7 e 8 são as que possuem o menor percentual de carga horária, com respectivamente 45, 120 e 150 horas. Com exceção da IES 3, que possui a maior carga horária com 675 horas.

Constata-se que com relação aos componentes curriculares associados ao estágio das instituições pesquisadas voltados para a educação infantil, há uma variedade de carga horária, onde a mínima é de sessenta horas e a máxima de cento e vinte horas. No quadro 2 a seguir apresentamos as instituições, as disciplinas, as cargas horárias e os períodos dos cursos de pedagogia voltados para a prática na educação infantil.

Quadro 2 - Relação das disciplinas de estágio.

\begin{tabular}{|c|l|c|c|}
\hline INSTITUIÇÃOO & \multicolumn{1}{|c|}{ DISCIPLINAS } & $\begin{array}{c}\text { CARGA } \\
\text { HORÁRIA }\end{array}$ & PERÍODO \\
\hline IES 1 & Prática de Ensino e Orientação de Estágio II & 105 horas & $6^{\circ}$ período \\
\hline IES 2 & $\begin{array}{l}\text { Prática Escolar com estágio supervisionado em } \\
\text { Edu Infantil I }\end{array}$ & 60 horas & $2^{-1}$ \\
\hline IES 3 & Estágio Supervisionado II & 90 horas & $6^{\circ}$ período \\
\hline IES 4 & Estágio curricular em educação infantil & 120 horas & $7^{\circ}$ período \\
\hline IES 5 & Estágio Supervisionado II & 120 horas & \\
\hline IES 6 & Estágio supervisionado em educação infantil I & 72 horas & $4^{\circ}$ período \\
\cline { 2 - 4 } & Estágio supervisionado em educação infantil II & 72 horas & $5^{\circ}$ período \\
\hline IES 7 & Estágio supervisionado em educação infantil & 120 horas & $5^{\circ}$ período \\
\hline IES 8 & Orientação ao estágio educação infantil & 90 horas & $1^{\circ}$ período \\
\hline IES 9 & Estágio Supervisionado II & 105 horas & $7^{\circ}$ período \\
\cline { 2 - 4 } & Estágio Supervisionado III & 120 horas & $8^{\circ}$ período \\
\hline
\end{tabular}

Fonte: Elaboração própria a partir dos estudos selecionados.

Na IES 6 a disciplina de estágio está dividida em dois momentos de setenta e duas horas cada, sendo respectivamente no $4^{\circ}$ e $5^{\circ}$ período do curso de pedagogia. $\mathrm{Na}$ IES 9 a disciplina de estágio educação infantil acontece concomitantemente com o estágio do ensino fundamental, no qual a carga horária do estágio II é de cento e cinco horas, e a de estágio III são cento e vinte horas, estando disponíveis no $7^{\circ}$ e $8^{\circ}$ períodos do curso.

Em relação às IES 2 e 5, não foi possível identificar o período em que o estágio é ofertado, pois esta informação não estava presente no projeto pedagógico. Nota-se que na IES 8 a disciplina se apresenta logo no início do curso de pedagogia, ou seja, no $1^{\circ}$ período, com as disciplinas específicas de educação infantil que também são ofertadas no início do curso.

${ }^{4}$ Não foi encontrado no Projeto Pedagógico dessa instituição o período das disciplinas. 
Nas demais, IES 1, 3, 6 e 7 o estágio se encontra entre o $4^{\circ}$ até o $6^{\circ}$ período do curso, ou seja, os estágios de educação infantil ocorrem no meio do curso de Pedagogia e coincidem com a oferta das disciplinas ditas "teóricas". Nas IES 4 e 9, a disciplina de estágio ocorre no $7^{\circ}$ e $8^{\circ}$ períodos, ou seja, no final do curso, mas, apesar disso, também coincidem com as disciplinas específicas teóricas. Assim, essa oferta do estágio junto às disciplinas teóricas pode trazer perspectivas de alteração da dicotomia que em muito ainda sobrevive nos cursos de formação inicial com a separação entre teoria e prática, propiciando uma reflexão da realidade com os pressupostos teóricos das disciplinas. Assim, devemos pontuar o esforço das instituições na adequação curricular dos cursos de pedagogia.

Para compreendermos de forma mais detalhada o que os cursos de Pedagogia estão apresentando enquanto disciplinas voltadas para a Educação Infantil, analisamos também as temáticas presentes nas ementas das disciplinas presentes anteriormente no quadro 1. Acompanhemos os dados do quadro 3 apresentado abaixo:

Quadro 3 - Temáticas centrais encontradas nas ementas

\begin{tabular}{|c|c|c|}
\hline Componente curricular & Temáticas centrais & IES \\
\hline Fundamentos da Educação Infantil & $\begin{array}{l}\text { A constituição das creches e pré- } \\
\text { escolas no Brasil; A legislação; As } \\
\text { políticas públicas; O financiamento } \\
\text { e a gestão democrática. }\end{array}$ & IES $1,2,3,6,7,9$ \\
\hline Infância, Cultura e Sociedade & $\begin{array}{l}\text { Aspectos históricos da infância; } \\
\text { processos de socialização; Infância e } \\
\text { Cultura; A infância na } \\
\text { contemporaneidade. }\end{array}$ & IES 4 e 8 \\
\hline Currículo na Educação Infantil & $\begin{array}{l}\text { Propostas Curriculares; Diretrizes } \\
\text { Curriculares Nacionais para a } \\
\text { Educação Infantil (DCNEI's) e } \\
\text { Referencial Curricular Nacional para } \\
\text { a Educação Infantil (RCNEI); } \\
\text { Planejamento na Educação Infantil; } \\
\text { Tendências pedagógicas; Avaliação; } \\
\text { O trabalho com as famílias. }\end{array}$ & IES $1,3,4,6,9$ \\
\hline A docência na Educação Infantil & $\begin{array}{l}\text { O trabalho pedagógico na educação } \\
\text { infantil; As rotinas - a organização } \\
\text { dos tempos e espaços; Projetos de } \\
\text { Trabalho; Relação entre cuidado e } \\
\text { educação; Construção de ambientes } \\
\text { de interações e relações. }\end{array}$ & IES $1,2,4,6,8$ \\
\hline Desenvolvimento Infantil & $\begin{array}{l}\text { Crescimento e desenvolvimento da } \\
\text { criança; a natureza biológica da } \\
\text { criança; os problemas de saúde na } \\
\text { infância; Higiene; Alimentação; } \\
\text { Aleitamento; Imunização; Acidentes } \\
\text { e maus-tratos na infância. }\end{array}$ & IES 3 e 5 \\
\hline Jogos e Brincadeiras & $\begin{array}{l}\text { A relação } \\
\text { brincadeira; }\end{array} \begin{array}{c}\text { jogo-brinquedo- } \\
\text { Concepções } \\
\text { antropológicas, psicológicas e } \\
\text { sociológicas do jogo; O conceito de } \\
\text { ludicidade; O uso de jogos com } \\
\text { crianças com necessidades } \\
\text { educativas especiais; Construção de }\end{array}$ & IES 3,6 e 9 \\
\hline
\end{tabular}




\begin{tabular}{|l|l|l|}
\hline & brinquedos. & \\
\hline Linguagem e Pensamento & A relação linguagem-pensamento; & IES 3 \\
& As múltiplas linguagens; & \\
Alfabetização e Letramento; A & & \\
& relação entre língua, cultura e & \\
sociedade. & O ensino de Artes para as crianças; & IES 4 \\
\hline Artes na Educação Infantil & A formação de professores e o & \\
& ensino de arte; Artes visuais no & \\
& Referencial Curricular Nacional de & \\
& Educação Infantil (RCNEI). & \\
\hline
\end{tabular}

Fonte: Elaboração própria a partir dos estudos selecionados.

A partir do quadro 3, buscou-se apresentar as principais discussões das temáticas presentes nas ementas dos componentes curriculares analisados. Verificou-se uma preocupação com a discussão sobre a importância de se pensar os fundamentos da educação infantil situando-a historicamente e sua relação com a contemporaneidade a partir da legislação e das políticas voltadas a essa etapa da educação básica. Essa discussão se relaciona à compreensão da criança enquanto um ser social e histórico, e que foi constituído como "sujeito de direitos".

Em relação às discussões sobre currículo na educação infantil, encontramos uma visão mais abrangente que engloba a apresentação de propostas curriculares variadas, há também a consideração das Diretrizes Curriculares Nacionais para a educação infantil, que são mandatórias, e que devem organizar as propostas curriculares nas nossas instituições de educação infantil em conjunto com a presença do Referencial Curricular Nacional de Educação Infantil.

As disciplinas envolvendo a docência na educação infantil com as temáticas das rotinas, Projetos de Trabalho e Construção de ambientes de interações e relações, são pontos importantes visando a estabelecer a relação entre cuidado e educação junto às crianças de zero a cinco anos. Essas temáticas vão ao encontro de uma Pedagogia da Infância que considera a importância da construção do conhecimento junto às crianças por meio dos projetos de trabalhos e do questionamento de rotinas rígidas por meio da organização do tempo e do espaço nas instituições de educação infantil.

Com uma presença menor nos currículos encontramos as disciplinas referentes aos Jogos e Brincadeiras, Linguagem e Pensamento e Artes na educação infantil. Essas disciplinas apareceram especificamente em três instituições e são muito importantes para tratarmos com as futuras professoras da educação infantil, já que o brincar é uma das linguagens principais da criança e também de produção das culturas infantis que se articula às discussões da disciplina de Linguagem e Pensamento ao relacionar 
desenvolvimento, aprendizagem e o brincar. A disciplina de Artes trabalha com o princípio das múltiplas linguagens e que se agrega a essa compreensão de uma criança que se expressa de formas variadas.

A temática do Desenvolvimento Infantil apareceu apenas em duas instituições e abordam questões relativas ao Crescimento e desenvolvimento da criança; a natureza biológica da criança; os problemas de saúde na infância; Higiene; Alimentação; Aleitamento; Imunização; Acidentes e maus-tratos na infância. São questões pouco enfatizadas nas instituições de ensino superior, mas que apresentam informações relevantes a respeito do desenvolvimento e da saúde da criança.

A partir dessas temáticas pudemos encontrar algumas lacunas nesses currículos dos cursos de pedagogia analisados, pois não há menção nas ementas a respeito das faixas etárias considerando as crianças de zero a três, ou seja, o trabalho com os bebês e as crianças pequenas na creche; e a faixa etária de quatro e cinco anos que inclui as crianças da chamada pré-escola. Assim, as temáticas presentes nas ementas e programas não contemplam explicitamente discussões a respeito das especificidades que envolvem o trabalho pedagógico com as diversas faixas etárias, considerando que em cada fase da vida as crianças apresentam especificidades que demandam das profissionais da educação infantil um saber adequado que possa responder às necessidades dessa criança.

Faz-se também necessário na organização das disciplinas que se discuta os aspectos relacionados à socialização das crianças, compreendendo o papel do adulto, da instituição, da família e das próprias crianças que também se socializam no processo de reprodução interpretativa, já destacado anteriormente nessa reflexão a partir das contribuições de Willian Corsaro (2011).

Encontramos apenas uma instituição que tinha em seu currículo constando como disciplina obrigatória discussões acerca do brincar e do jogo. O brincar constitui uma linguagem essencial da criança a partir da qual ela busca um entendimento do mundo adulto que a cerca. $\mathrm{O}$ conhecimento referente às culturas infantis, bem como a observação e documentação das crianças nos momentos de brincadeira pode fornecer elementos importantes para a prática pedagógica cotidiana nas instituições de educação infantil, e os cursos de pedagogia precisam fornecer o acesso e reflexão a esse conhecimento sobre a criança.

\section{Considerações Finais}


Entende-se que as disciplinas disponíveis nos cursos de Pedagogia com a temática da educação infantil são importantes no auxílio para se alcançar uma formação de qualidade, no sentido de formar professoras competentes para atuarem na educação infantil, mas para que isso aconteça é necessária uma compreensão das especificidades desta modalidade da educação básica.

Considerando os currículos dos projetos pedagógicos dos cursos de Pedagogia, pudemos notar uma variedade de disciplinas específicas para a educação infantil em relação às nomenclaturas que são utilizadas em cada instituição. Isso não contribui para a constituição de um corpus teórico específico voltado para o campo da educação infantil e a formação das professoras, dificultando a análise dos diversos componentes existentes, já que cada instituição propõe as disciplinas de acordo com o seu quadro docente e o espaço que é concedido a essas disciplinas, que se configuram como disputas e tensões no campo da constituição de cada currículo.

Em relação à quantidade numérica de disciplinas ofertadas, constatamos que a presente pesquisa vai ao encontro da análise realizada pela pesquisadora Kishimoto (2005), na qual apresenta que os cursos de formação inicial em pedagogia possuem uma falta de especificidade em relação à modalidade da educação infantil, decorrente do fato que mais da metade da carga horária está tomada por disciplinas voltadas para a formação do pedagogo, e também, para os campos da Matemática, Ciências, Português, História, Geografia, Educação Física e Artes, o que gera um modelo de curso que reproduz práticas do Ensino Fundamental.

Deste modo, constatamos que em relação às disciplinas de formação específica de educação infantil presentes nos currículos das universidades mineiras pesquisadas há uma variância de 3,75 a 9,95\% em relação à carga horária total do curso de disciplinas voltadas para educação infantil. O menor percentual foi encontrado apenas nas IES 7 e 9. As demais, com exceção da IES 9, ofertam 9,95\% das suas disciplinas da área da educação infantil.

Em contrapartida, observamos que no curso de pedagogia oferecido na IES 3 há uma quantidade maior de disciplinas, representando $17,67 \%$ da carga horária total do curso de pedagogia voltada à educação infantil, com isso podemos dizer que entre as universidades federais de Minas Gerais pesquisadas, essa instituição apresenta uma série de disciplinas a partir das quais se aumenta a possibilidade de formar uma profissional mais qualificada para atuar na educação infantil, considerando as especificidades inerentes a essa faixa etária. 
A carga horária dos estágios na maioria das instituições apresenta um total de horas superior a noventa. As disciplinas de estágio em $90 \%$ das instituições estão sendo ofertadas juntamente com as disciplinas específicas (ou ditas teóricas) de educação infantil, e isso é um ponto a ser considerado, pois pode contribuir para a minimização da dicotomização entre teoria e prática. Assim, devemos pontuar o esforço das instituições na adequação curricular dos cursos de pedagogia.

No entanto, ao comparar a carga horária das disciplinas voltadas ao ensino fundamental no currículo de pedagogia, verificou-se uma semelhança em relação a todas as IES no que se refere a uma carga horária menor para as disciplinas de educação infantil. Isso acarreta uma formação mais genérica associada às temáticas e metodologias do ensino fundamental em detrimento das especificidades que compõem a docência na educação infantil. Mas é importante salientar que as disciplinas que compõem essas dinâmicas curriculares apresentam discussões relevantes acerca da criança, da infância e da educação infantil, apesar de comporem quantitativamente um número menor de disciplinas quando consideradas na porcentagem total de carga horária oferecida pelos cursos.

Uma questão premente a ser revisada na elaboração dessas disciplinas é a relação cuidar-educar, evitando as dicotomizações que, inclusive, são reforçadas pelas funções exercidas na profissão: auxiliar/monitora (cuida) e professora (educa). Essa discussão acerca do cuidar-educar, tanto para as crianças de zero a três quanto para as crianças de quatro a cinco anos, pode ser questionada e revista a partir das disciplinas envolvendo o currículo e a prática pedagógica ao enfocar as questões da organização da rotina e do próprio currículo da educação infantil, visando evitar a separação entre as atividades voltadas para o corpo (cuidar), e àquelas voltadas à mente/intelecto (educar).

Quisemos com essa discussão mostrar o espaço ocupado pelas disciplinas presentes nos currículos dos cursos de pedagogia das instituições federais mineiras que estão voltadas às discussões da área educação infantil. Para além do que já está sendo ofertado é preciso ampliar esse universo, principalmente em relação às práticas pedagógicas voltadas aos bebês e às questões de saúde e desenvolvimento das crianças. Encontramos essa discussão sobre saúde e desenvolvimento infantil em apenas uma das instituições analisadas. É preciso também articular as disciplinas de conteúdos específicos, como matemática, língua portuguesa, ciências, geografia e artes às formas de aprendizagem e desenvolvimento das crianças da educação infantil, com práticas 
pedagógicas que valorizem as linguagens e as culturas infantis em detrimento do uso de metodologias associadas ao processo de escolarização do ensino fundamental.

No Parecer n. 5/2005 de aprovação das Diretrizes Curriculares Nacionais para o Curso de Pedagogia, encontramos uma discussão a respeito das especificidades do modo de aprendizagem e desenvolvimento das crianças de zero a cinco anos que se manifestam a partir de linguagens e códigos próprios dessa faixa etária. O documento chama a atenção para o fato da aprendizagem desse grupo etário ser diferente das crianças de 7 a 10 anos e finaliza apontando que,

Estudos vêm demonstrando que o desconhecimento dessas particularidades, entre outras, tem gerado procedimentos impróprios e até de violência às linguagens e necessidades do educando. Daí decorre a exigência precípua de o curso de Pedagogia examinar o modo de realizar trabalho pedagógico, para a educação da infância a partir do entendimento de que as crianças são produtoras de cultura e produzidas numa cultura, rompendo com uma visão da criança como "vir a ser" (BRASIL, 2005, p.13).

Nesse sentido, encontramos ainda lacunas no que se refere à organização das universidades quanto à área da educação infantil a ser contemplada na formação das futuras professoras nos cursos de pedagogia, e que reclama por políticas governamentais que possam contribuir para a constituição de um campo de formação específico. Neste sentido, cabe aqui ressaltar que tanto a formação inicial quanto a continuada de professoras da educação infantil, seja pelo curso de Pedagogia, Normal Superior ou cursos de formação continuada, precisam contribuir para a reflexão sobre a efetividade de se ter uma educação infantil pautada em uma pedagogia que respeite a criança, para que se evite a reprodução de práticas escolarizantes com o predomínio da cultura escrita e a cobrança de resultados associados à lógica do ensino fundamental.

Experimentar e explorar a própria infância como um modo diferente de se pensar a Pedagogia e a própria criança, reconhecendo sua diversidade; observando as ações e interações infantis na produção de suas culturas infantis e valorização das suas atividades; compreendendo que as crianças são sujeitos ativos que constroem o conhecimento de forma contextualizada; propondo atividades significativas e prazerosas; possibilitando a construção da autonomia da criança. Uma pedagogia que considere a infância implica na escuta atenta da criança, no diálogo e interação, considerando a criança como ator social, ou seja, ativo, competente, que busca 
interpretar o mundo adulto, que constrói saberes e culturas a partir das suas múltiplas linguagens por meio de um conhecimento que se constrói nas relações.

\section{Referências}

BRASIL. Ministério da Educação. Diretrizes Curriculares Nacionais para o curso de Pedagogia (Parecer CNE N.5/2005). p.01-24.

CORSARO, William Arnold. Sociologia da infância. Tradução: Lia Gabriele Regius Reis; Rev. Técnica: Maria Letícia B. P. Nascimento. São Paulo, SP: Artmed, 2011.

FOMOSINHO, João. A universidade e a formação de educadores de infância: potencialidades e dilemas. In: MACHADO, Maria Lúcia de. Encontros e Desencontros na Educação Infantil. São Paulo: Cortez, 2008. p.169-188.

GOMES, Romeu. Análise dos dados em Pesquisa Qualitativa. In: Minayo, Cecília de Souza (org). Pesquisa Social: teoria, método e criatividade. Petrópolis (RJ): Vozes. 23 ${ }^{\text {a }}$ ed. 1994.

GOODSON, Ivor. F. A construção social do currículo. Portugal, Educa, 1997.

JAMES, Allison \& JAMES, Adrian L. Constructing Childhood: theory, policy and social practice. New York: Palgrave Macmillan. 2004.

KISHIMOTO, Tizuko M. Pedagogia e a formação de professores (as) de Educação Infantil. In: Pró-Posições, v. 16, n.3 (48), p.181-193, set/dez. 2005.

KISHIMOTO, Tizuko Morchida. Encontros e desencontros na formação dos profissionais de educação infantil. In: __ MACHADO, Maria Lucia de A. (org.). Encontros e Desencontros em Educação Infantil. 3. ed. - São Paulo: Cortez, 2008.

KRAMER, Sonia. Formação de Profissionais da Educação infantil. In: MACHADO, Maria Lúcia de. Encontros e Desencontros na Educação Infantil. São Paulo: Cortez, 2005.

MACEDO, Sidnei R. Currículo: campo, conceito e pesquisa. Petrópolis (RJ): Vozes, 2012. $5^{\mathrm{a}} \mathrm{ed}$.

MOLLO-BOUVIER, Suzzane. Transformação nos modos de socialização das crianças: uma abordagem sociológica. In: Revista Educação \& Sociedade. N. 91. Vol. 26. Mai/ago. 2005..

PLAISANCE, Eric. Para uma sociologiada pequena infância. In: Revista Educação \& Sociedade, Campinas, vol. 25, n. 86, p.221-241, Abril. 2005. 
PROUT, Alan. The future of childhood: towards the interdisciplinary study of children. Great Britain: RoutledgeFalmer. 167 p. 2005.

SARMENTO, Manuel Jacinto. Gerações e Alteridade: interrogações a partir da sociologia da infância. In: Revista Educação \& Sociedade. N. 91. Vol. 26. Mai/ago. 2005.

SARMENTO, Manuel Jacinto. Culturas infantis e Interculturalidade. In: DORNELLES, Leni (org). Culturas da Infância. Petrópolis (RJ): Vozes, 2007.

SIROTA, Régine. Emergência de uma Sociologia da Infância: evolução do objeto e do olhar. In: Cadernos de Pesquisa, $n^{\circ} 112$, p. 07-31, março/2001.

\section{Como referenciar este artigo}

OLIVEIRA, Fabiana de.; ANDRADE, Giovana Gomes de. O curso de pedagogia nas universidades federais do Estado de Minas Gerais: reflexões acerca do espaço da educação infantil nos currículos de formação inicial. Revista Ibero-Americana de Estudos em Educação, Araraquara, v.12, n.1, p. 258-277, 2017. Disponível em: <http://dx.doi.org/10.21723/riaee.v12.n1.8233 >. E-ISSN: 1982-5587.

Data de submissão: nov/2015

Aprovação final: dez/2016 